\title{
Association Between Psychological Disorders and Irritable Bowel Syndrome
}

\author{
Salman Umrani ${ }^{1}$, Waleed Jamshed ${ }^{2}$, Amber Rizwan ${ }^{3}$ \\ 1. Internal Medicine, University Hospital of North Tees, Stockton-on-Tees, GBR 2. Internal Medicine, Central Park \\ Medical College, Lahore, PAK 3. Family Medicine, Jinnah Post Graduate Medical Center, Karachi, PAK
}

Corresponding author: Amber Rizwan, amber_aljazeera109@hotmail.com

\section{Abstract \\ Introduction}

Irritable bowel syndrome (IBS) is an idiopathic, functional and chronic relapsing disorder. Physiological and psychological variables have been linked with etiology of IBS. In this study, we will determine the prevalence of IBS in local setting and its association with anxiety and depression.

\section{Materials and methods}

This cross-section study was conducted in multiple cities of Pakistan. One thousand and seven hundred and sixty $(1,760)$ participants from general population between the age group 18 to 50 were enrolled in the study after informed consent. Diagnosis of IBS was made by assessing participants via ROME III criteria. Hospital anxiety and depression scale (HADS) was used to determine if the participants had anxiety and depression.

\section{Results}

IBS was present in 456 (25.9\%) participants. IBS was significantly more prevalent in females compared to males. Anxiety was significantly more common in participants with IBS compared to participants without IBS (53.0\% vs. 23.0\%; p-value < 0.00001). Similarly, depression was significantly more common in participants with IBS $(50.6 \%$ vs. $21.5 \%$; p-value $<0.00001)$.

\section{Conclusion}

IBS is very common in Pakistan, but rarely diagnosed. It is important anyone, particularly at young age, presenting with diarrhea or constipation should be evaluated for IBS. Simultaneously, patients diagnosed with IBS should be screened for anxiety and depression, and managed accordingly.

Review began 04/09/2021 Review ended 04/13/2021 Published 04/16/2021

\section{๑) Copyright 2021}

Umrani et al. This is an open access article distributed under the terms of the Creative Commons Attribution License CC-BY 4.0., which permits unrestricted use, distribution, and reproduction in any medium, provided the original author and source are credited.
Categories: Psychology, Gastroenterology, Public Health Keywords: irritable bowel syndrome, anxiety, depression

\section{Introduction}

Irritable bowel syndrome (IBS) affects 1 out of 10 persons of the general population worldwide [1]. IBS is an idiopathic, functional and chronic relapsing disorder, which may be caused due to psychosocial factors; altered motility, and/or altered sensory function of gastrointestinal tract [2]. IBS is characterized by abdominal pain and discomfort with frequent episodes of diarrhea and constipation [3]. It can be diagnosed clinically, based on exclusion of any organic disease [4]. Major causative agents that have been observed in occurrence of IBS includes prolonged infectious diseases, smoking, mucosal markers of inflammation, female gender, hypochondriasis and posttraumatic syndrome disease, etc. [5].

Physiological and psychological variables have been linked with etiology and severity of irritable bowel syndrome. Various studies have reported a high prevalence of psychiatric disorders in patients with IBS $[6,7]$. Globally lot of work has been done to establish association between IBS and psychological disorders. However, in developing countries, there is very limited data related to IBS and risk factors associated with it. In this study, we will determine the prevalence of IBS and its association with psychological disorders such as anxiety and depression.

\section{Materials And Methods}

This cross-section study was conducted in multiple cities of Pakistan. One thousand and seven hundred and sixty $(1,760)$ participants from general population between the age group 18 to 50 , of either gender, were enrolled in the study after informed consent. Participant's age and gender were noted in self-structured questionnaire. Diagnosis of irritable bowel syndrome was made via ROME III criteria [8]. ROME III criteria define IBS as recurrent abdominal pain or discomfort for at least three days/months during the last three months associated with two or more of the following symptoms: improvement of pain with defecation, onset 


\section{Cureus}

associated with a change in frequency of stool and onset associated with change in form of stool [8]. Patients diagnosed with IBS based on Rome III criteria were labelled as case group and patients negative for IBS was included as reference group.

To assess anxiety and depression among participants, Hospital anxiety and depression scale (HADS) was used. Score of less than eight (08) on each sub-scale of anxiety and depression indicated pathological anxiety and depression [9]. Interviewer filled the questionnaire after explaining each question to participant in the native language.

Statistical analysis was done using SPSS v. 24.0 (IBM Corporation, Armonk, NY, United States). Continuous variables were analyzed via descriptive statistics and were presented as means and standard deviations (SDs) while categorical data were presented as frequency and percentage. Chi-square was applied as appropriate. p-value of less than 0.05 meant that the difference between the groups is significant and the null hypothesis is void.

\section{Results}

IBS was present in 456 (25.9\%) participants. IBS was significantly more prevalent in females compared to males $(61.7 \%$ vs. $38.3 \%$; p-value < 0.00001$)$. IBS was common in participants aged between 18 and 30 years (44.0\%) (Table 1).

\begin{tabular}{|c|c|c|c|}
\hline Characteristics & IBS positive $(n=456)$ & IBS negative $(n=1,304)$ & p-value \\
\hline \multicolumn{4}{|l|}{ Gender (\%) } \\
\hline Male & 175 (38.3) & 682 (52.3\%) & \multirow{3}{*}{$<0.00001$} \\
\hline Female & $281(61.7)$ & 622 (47.7\%) & \\
\hline \multicolumn{3}{|l|}{ Age in years $(\%)$} & \\
\hline $18-30$ & 201 (44.0\%) & 401 (30.7\%) & \multirow{3}{*}{$<0.00001$} \\
\hline $31-40$ & 155 (33.9\%) & $341(26.1 \%)$ & \\
\hline $41-50$ & 100 (21.9\%) & $562(43.0 \%)$ & \\
\hline
\end{tabular}

\section{TABLE 1: Characteristics of case and control group.}

IBS; irritable bowel syndrome

In participants who were diagnosed with IBS based on ROME III criteria, the most common symptom was bloating (68.4\%), followed by frequency of stool of more than 3 per day (44.0\%) and abdominal pain relieved by passing stool (38.5\%) (Table 2).

\begin{tabular}{|c|c|c|}
\hline Irritable bowel syndrome symptoms & Frequency & Percentages \\
\hline Bloating & 312 & 68.4 \\
\hline Stool more than three per day & 201 & 44.0 \\
\hline Abdominal Pain relieved by passing stool & 176 & 38.5 \\
\hline Loose or watery stool & 172 & 37.7 \\
\hline Stool less than three per week & 152 & 33.3 \\
\hline Mucus in stool & 62 & 13.5 \\
\hline
\end{tabular}

TABLE 2: Irritable bowel syndrome symptoms.

Anxiety was significantly more common in participants with IBS compared to participants without IBS (53.0\% vs. $23.0 \%$; p-value $<0.00001)$. Similarly, depression was significantly more common in participants with IBS (50.6\% vs. $21.5 \%$; p-value, $<0.00001)$ (Table 3). 


\section{Cureus}

\begin{tabular}{|c|c|c|c|c|c|c|}
\hline \multirow{2}{*}{ HADS score } & \multicolumn{3}{|l|}{ Anxiety } & \multicolumn{3}{|l|}{ Depression } \\
\hline & IBS positive $(n=456)$ & IBS negative $(n=1,304)$ & p-value & IBS positive $(n=456)$ & IBS negative $(n=1,304)$ & p-value \\
\hline Less than 8 & $242(53.0 \%)$ & 301 (23.0\%) & \multirow{2}{*}{$<0.00001$} & $231(50.6 \%)$ & $281(21.5 \%)$ & \multirow{2}{*}{$<0.00001$} \\
\hline More than 8 & $214(47.0 \%)$ & $1003(77.0 \%)$ & & 225 (49.4\%) & 1023 (78.5\%) & \\
\hline
\end{tabular}

TABLE 3: Anxiety and depression in case and control group.

HADS: hospitalized anxiety and depression scale.

\section{Discussion}

In this study, the prevalence of IBS was found to be more common in young people between the ages of 1830 (44\%). Majority of the participants with IBS in our study were reported to have symptoms of anxiety and depression. In our study, in patients who were diagnosed with IBS, the most common complaint was bloating (68.4\%), followed by increase frequency of stool of more than three per day (44.0\%) and abdominal pain relieved by passing stool (38.5\%). American Gastroenterology Association (AGA) reported similar findings in a recent technical review [10]. It showed that psychological stress is known to aggravate gastrointestinal symptoms leading to severe diarrhoea, abdominal discomfort, etc. Moreover, psychological and psychiatric comorbidity is generally found among IBS patients. Women were reported to show supremacy over men in terms of having IBS, which is also believed to be present in women in the West [11].

Drossman et al. explored the association between IBS and psychological comorbidities, and found a positive link between the two. He found that $60 \%$ of patients with IBS have psychosocial problems [12]. Even though the exact origin of IBS is difficult to track down, it is believed that improper functioning of brain-gut pathways may be responsible for causing the disease [13]. This points towards the idea that abdominal symptoms have a tendency to affect anxiety and depression. These factors, in turn, affect the physiological factors [14]. Some other researches were able to prove the positive correlation between IBS and psychological comorbidities such as anxiety and depression [15-17]. However, there were some researches that could not find any such association [15,18-19].

A recent study by the Anxiety and Depression Association of America shown that seven out of 10 United States adults are reported to undergo stress and anxiety moderately every day [20]. Stress is an unavoidable and existing part of our life [21]. Recent studies have shown high prevalence of stress in university students $[22,23]$. Along with stress and anxiety, depression is also believed to be faced by a lot of college students. Wolfran et al. Stated in his study published in 2010 that in the USA, approximately $10 \%$ of university students are either diagnosed with depression, or were treated for it [24]. This correlates with findings of our study, which shows that the prevalence of IBS was more frequent in between age group of 18-30 years, which is a university-going age.

Based on our study, we suggest that it is extremely important to provide psychiatric evaluation to anyone showing IBS-like symptoms, particularly in young population. As psychiatric symptoms can be presenting symptoms in patients with IBS, psychiatrists and psychologists should also be trained to screen for IBS, particularly in young population. Regular screening in universities and workplace for IBS may help in early diagnosis of IBS and may help alleviate the risk factors such as anxiety and stress, early in the course of disease.

To the best of our knowledge, it is the first study in local setting that studies the association of anxiety and depression with IBS. Considerably large sample size makes the finding of study reliable. Since data was collected from multiple cities, the sample was diverse. However, because of nature of study design, definite association cannot be established between IBS and psychological issues. Prospective studies are needed to consolidate the findings of our study.

\section{Conclusions}

In this study, the prevalence of IBS was considerably high and prevalence of anxiety and depression in patients with IBS was also considerably high. It is important anyone presenting with gastrointestinal symptoms should be screened for diagnosis of IBS. After confirmation of IBS, patient should undergo complete psych evaluation for anxiety, stress and depression. Management of IBS should include management of anxiety, stress and depression as well.

\section{Additional Information}

\section{Disclosures}


Human subjects: Consent was obtained or waived by all participants in this study. Jinnah Sindh Medical University issued approval JSMU/S/IRB/2019-033. Animal subjects: All authors have confirmed that this study did not involve animal subjects or tissue. Conflicts of interest: In compliance with the ICMJE uniform disclosure form, all authors declare the following: Payment/services info: All authors have declared that no financial support was received from any organization for the submitted work. Financial relationships: All authors have declared that they have no financial relationships at present or within the previous three years with any organizations that might have an interest in the submitted work. Other relationships: All authors have declared that there are no other relationships or activities that could appear to have influenced the submitted work.

\section{References}

1. Black CJ, Ford AC: Global burden of irritable bowel syndrome: trends, predictions and risk factors . Nat Rev Gastroenterol Hepatol. 2020, 17:473-86. 10.1038/s41575-020-0286-8

2. Creed F: Review article: the incidence and risk factors for irritable bowel syndrome in population-based studies. Aliment Pharmacol Ther. 2019, 50:507-16. 10.1111/apt.15396

3. Weaver KR, Melkus GD, Henderson WA: Irritable bowel syndrome. Am J Nurs. 2017, 117:48-55. 10.1097/01.NAJ.0000520253.57459.01

4. Spiller R, Garsed K: Postinfectious irritable bowel syndrome. Gastroenterology. 2009, 136:1979-88. 10.1053/j.gastro.2009.02.074

5. Klem F, Wadhwa A, Prokop LJ, et al.: Prevalence, risk factors, and outcomes of irritable bowel syndrome after infectious enteritis: a systematic review and meta-analysis. Gastroenterology. 2017, 152:1042-1054.e1. 10.1053/j.gastro.2016.12.039

6. Surdea-Blaga T, Băban A, Dumitrascu DL: Psychosocial determinants of irritable bowel syndrome. World J Gastroenterol. 2012, 18:616-26. 10.3748/wig.v18.i7.616

7. Toner BB, Garfinkel PE, Jeejeebhoy KN: Psychological factors in irritable bowel syndrome. Can J Psychiatry. 1990, 35:158-61. 10.1177/070674379003500210

8. Rishi P, Rishi E, Maitray A, Agarwal A, Nair S, Gopalakrishnan S: Hospital anxiety and depression scale assessment of 100 patients before and after using low vision care: A prospective study in a tertiary eye-care setting. Indian J Ophthalmol. 2017, 65:1203-8. 10.4103/ijo.IJO_436_17

9. Lépine JP, Godchau M, Brun P, Lempérière T: Evaluation of anxiety and depression among patients hospitalized on an internal medicine service. Ann Med Psychol. 1985, 143:175-89.

10. Drossman DA, Camilleri M, Mayer EA, Whitehead WE: AGA technical review on irritable bowel syndrome . Gastroenterology. 2002, 123:2108-31. 10.1053/gast.2002.37095

11. Gwee KA: Irritable bowel syndrome in developing countries--a disorder of civilization or colonization? . Neurogastroenterol Motil. 2005, 17:317-24. 10.1111/j.1365-2982.2005.00627.x

12. Levy RL, Olden KW, Naliboff BD, Bradley LA, Francisconi C, Drossman DA, Creed F: Psychosocial aspects of the functional gastrointestinal disorders. Gastroenterology. 2006, 130:1447-58. 10.1053/j.gastro.2005.11.057

13. Kennedy PJ, Clarke G, Quigley EM, Groeger JA, Dinan TG, Cryan JF: Gut memories: towards a cognitive neurobiology of irritable bowel syndrome. Neurosci Biobehav Rev. 2012, 36:310-40. 10.1016/j.neubiorev.2011.07.001

14. Stasi C, Rosselli M, Bellini M, Laffi G, Milani S: Altered neuro-endocrine-immune pathways in the irritable bowel syndrome: the top-down and the bottom-up model. J Gastroenterol. 2012, 47:1177-85. 10.1007/s00535-012-0627-7

15. Alander T, Heimer G, Svardsudd K, Agreus L: Abuse in women and men with and without functional gastrointestinal disorders. Dig Dis Sci. 2008, 53:1856-1864. 10.1007/s10620- 007-0101-1

16. Cho HS, Park JM, Lim CH, et al.: Anxiety, depression and quality of life in patients with irritable bowel syndrome. Gut Liver. 2011, 5:29-36. 10.5009/gnl.2011.5.1.29

17. Savas LS, White DL, Wieman M, et al.: Irritable bowel syndrome and dyspepsia among women veterans: prevalence and association with psychological distress. Aliment Pharmacol Ther. 2009, 29:115-25. 10.1111/j.1365-2036.2008.03847.x

18. Berman S, Suyenobu B, Naliboff BD, et al.: Evidence for alterations in central noradrenergic signaling in irritable bowel syndrome. Neuroimage. 2012, 63:1854-63. 10.1016/j.neuroimage.2012.08.028

19. Lee YY, Waid A, Tan HJ, Chua SB, Whitehead WE : Validity and reliability of the Malay-language translation of the Rome III Diagnostic Questionnaire for irritable bowel syndrome. J Gastroenterol Hepatol. 2012, 27:746-50. 10.1111/j.1440-1746. 2011.06943.x

20. Physical activity reduces stress. Understanding the Facts Reports . Accessed: 23 March 2021: https://adaa.org/understanding-anxiety/related-illnesses/other-related-conditions/stress/physical-activityreduces-st.

21. Blanco C, Okuda M, Wright C, Hasin DS, Grant BF, Liu SM, Olfson M: Mental health of college students and their non-college-attending peers: results from the National Epidemiologic Study on Alcohol and Related Conditions. Arch Gen Psychiatry. 2008, 65:1429-37. 10.1001/archpsyc.65.12.1429

22. Gillman JL, Kim HS, Alder SC, Durrant LH: Assessing the risk factors for suicidal thoughts at a nontraditional commuter school. J Am Coll Health. 2006, 55:17-26. 10.3200/JACH.55.1.17-26

23. Mackenzie S, Wiegel JR, Mundt M, et al.: Depression and suicide ideation among students accessing campus health care. Am J Orthopsychiatry. 2011, 81:101-7. 10.1111/j.1939-0025.2010.01077.x

24. Depression Care: Using the Chronic Care Model in a University Health Center ([PowerPoint]). American College Health Association,Philadelphia,PA. (2010). Accessed: 23 March 2021: http://www.acha.org/AnnualMeeting/handouts10.cfm. 